\title{
Post Infectious Glomerulonephritis - Rare, but Reversible Cause of Acute Kidney Injury During Pregnancy
}

De Zoysa HDJ ${ }^{*}$, Weerakkody RM and Peranantharajah T

Jaffna Teaching Hospital, Jaffna, Sri Lanka

*Corresponding author: De Zoysa HDJ, Jaffna Teaching Hospital, Jaffna, Sri Lanka, E-mail: jeewakadezoysa@yahoo.com

Received date: August 23, 2017; Accepted date: October 18, 2017; Published date: October 23, 2017

Copyright: $@ 2017$ De Zoysa HDJ, et al. This is an open-access article distributed under the terms of the Creative Commons Attribution License, which permits unrestricted use, distribution, and reproduction in any medium, provided the original author and source are credited.

\begin{abstract}
Acute glomerulonephritis caused by Group A beta hemolytic streptococci and other organisms such as staphylococcus and gram negative bacteria is a rare occurrence in pregnancy. It should be considered in differential diagnosis in pregnant lady presenting with body edema, hematuria and reduced urine output.
\end{abstract}

Keywords: Pregnancy; Postinfectious glomerulonephritis; Acute kidney injury; Dialysis

\section{Introduction}

Group A-beta hemolytic streptococcus and other organisms such as staphylococcus can cause pharyngitis and skin sepsis in patients. Similar to their non-pregnant counter parts, it produces self-limited disease in pregnant patient. Rheumatic fever and postinfectious glomerulonephritis (PIGN) are well known complications of the infection. The pregnant patients usually acquire infection via contact with children of school going age [1,2]. Early diagnosis of these infections in pregnant women is very important to prevent complications.

\section{Case Report}

A 31 year old pregnant mother with period of amenorrhea (POA) 37 weeks+3 days, $\mathrm{P} 3 \mathrm{C} 2$, was transferred from local hospital for further management of acute kidney injury. Current pregnancy was complicated with pregnancy induced hypertension (PIH) for which she was on methyldopa $250 \mathrm{mg}$ bd and aspirin $150 \mathrm{mg}$ nocte. She had fairly good blood pressure control prior to the current presentation. Her previous two pregnancies were uncomplicated and fetuses were delivered vaginally. She presented to local hospital with dysuria and reduced urine output for 2 days duration. Patient had mild difficulty in breathing but she did not complain of hematuria, abdominal pain, headache or visual disturbances.

On examination, patient was afebrile but had mild dyspnea. Blood pressure was normal $(120 / 76 \mathrm{mmHg})$. Saturation was normal on air. There were multiple small skin infections noted on both lower limbs below the knee. Patient had bilateral basal fine crepitation and pitting ankle edema. Rest of the physical examination was normal.

Our differential diagnosis for this patient was pre-eclampsia, PIGN, Leptospirosis and rapidly progressive glomerulonephritis. She had albunimuria of +1 , microcytic hypochromic anemia $(\mathrm{Hb} 8.3 \mathrm{~g} / \mathrm{dl})$ with normal white cell and platelet counts $\left(324,000 \mathrm{~mm}^{3}\right)$. Urine microscopy revealed red cells and casts. Blood urea $(15.3 \mathrm{mmol} / \mathrm{l})$ and serum creatinine $(468 \mathrm{mmol} / \mathrm{l})$ were high on admission and progressively improved during hospital stay. On admission urine protein creatinine ratio was 0.82 . Ultrasound scan of the abdomen showed acute renal parenchymal changes, with swollen kidneys with low echogenicity. ASOT was $<200 \mathrm{iu} / \mathrm{ml}$. Liver enzymes (AST $29 \mathrm{u} / \mathrm{l} \&$ ALT $27 \mathrm{u} / \mathrm{l})$ were normal but patient had hypoalbuminaemia $(18 \mathrm{~g} / \mathrm{l})$. Normal liver enzymes and normal platelet levels excluded HELLP syndrome. It further excluded pregnancy related microangiopathic hemolytic anemias such as hemolytic uremic syndrome. She did not the full fill the definition for Pre-eclampsia as she already had the gestational hypertension prior to the admission and there was absence of significant proteinuria and end organ damage due to hypertension in this patient. Normal bilirubin $(15 \mu \mathrm{mol} / \mathrm{l})$, lack of exposure history and active urine sediment makes Leptospirosis an unlikely cause. RPGN during pregnancy is quite rare, and the prompt response to low dose steroids makes RPGN very unlikely. Finally PIGN secondary to skin sepsis was diagnosed clinically and other differential diagnoses were excluded. We did not perform a renal biopsy, as the patient was improving with steroids. ANA was negative; C3 and C4 levels were normal; (which was performed on day 4 of the illness). We did not perform anti-neutrophilic cytoplsmic antibodies (ANCA), antinicotinamide adenine dinucleotidase (anti-NAD), antihyaluronidase (AHase), and anti-DNAse B due to economic constrains or local unavailability.

Patient underwent emergency LSCS on following morning and healthy baby was delivered. She received four cycles of emergency hemodialysis. Any possible sepsis was treated with IV Ceftriaxone $1 \mathrm{~g}$ per $8 \mathrm{~h}$ (the blood and urine cultures later found to be negative) was given for 10 days. Prednisolone $30 \mathrm{mg}$ mane was started on $6^{\text {th }}$ day of admission. Patient improved with the treatment. Mother and new born baby were safely discharged. She was followed up at the nephrology clinic each fortnight with serum creatinine and urine full report. At the end of six weeks she had normal creatinine (78 umol/l), normal UFR, and a urine protein creatinine ratio of 0.11 . Once again, due to normal kidney functions we opted out for a renal biopsy. Four months postpartum she is well with normal renal functions.

\section{Discussion}

Post-infectious glomerulonephritis (PIGN) is a usually-benign, transient condition, that can rarely progress to end stage kidney disease [3]. It is commonly caused by group A beta hemolytic Streptococci, but other organisms, such as staphylococcus and gram negative bacterial infections are also emerging as causative organisms 
[4]. Group A beta hemolytic Streptococcus infection in pregnancy rarely causes PIGN. The incidence is estimated at 1:40,000 [1]. M protein serotype of Streptococcus pyogenes, especially type 12, nephritogenic strain identified as a causative factor of PIGN [5].

PIGN usually develops 10 days after the pharyngitis, and 21 days after the skin sepsis due to group A streptococcal infection [5]. Morphological and clinical features suggest that acute PIGN is an immune mediated disease but mechanism of antigen-antibody interaction is still not understood.

The disease is now rare in industrialized nations, but in the developing world, the incidence of PIGN ranges between 9.5 and 28.5 cases per 100,000 individuals per year.

Acute presentation varies from asymptomatic glomerulonephritis to nephritic syndrome. The diagnosis of PIGN is based on positive throat culture, hematuria, positive ASOT titre and decreased C3 and C4. A normal ASOT titre is seen in $15-20 \%$ of patient with streptococcal infection especially skin involvement [5]. The above data for nonstreptococcal glomerulonephritis is lacking or widely dependent on the causative organism. In our patient, renal biopsy was not done as she had clinical evidence of PIGN, as well as the rapid response shown to steroids.

Hemolytic uremic syndrome (HUS) of the pregnancy is a differential diagnosis of the AKI in late pregnancy. Normal coagulation, normal platelet levels, normal LDH levels and blood picture excluded this diagnosis; Leptospirosis is another common infection in the tropics that cause AKI. Presentation is similar, with fever, prostration, dwindling urine outputs, dark colored urine and jaundice. Lack of exposure, normal platelets, normal liver profile and finally, the negative leptospirosis antibody test excluded the diagnosis. Severe HUS and leptospirosis (associated with pulmonary hemorrhages) [6] have been shown to respond to plasmapheresis, which inturn a method of treatment for rapidly progressive glomerulonephritis. Thus, starting plasmapheresis on severe AKI in pregnancy has some merit, but was not available for our patient.

Treatment is usually supportive for glomerulonephritis unless acute kidney injury fails to recover even after eradication of infection. It can be prevented by early antibiotic treatment (within first $36 \mathrm{~h}$ ).
Prophylactic antibiotic should be given to people at risk for infection in pregnancy.

Prognosis is excellent in children but adults with debilitating illnesses such as diabetes and malnutrition develops complications such as uremia (60\%), congestive heart failure (40\%), and proteinuria in the nephrotic range (20\%). Death may occur in as many as 20 to $25 \%$ of these patients [7]. In pregnancy, PIGN can cause fetal loss and preeclampsia if the renal function does not return to normal [8].

\section{Conclusion}

This case illustrates that when pregnant mother presents with clinical features of nephritic syndrome, PIGN should be considered in the differential diagnosis. Early identification and treatment with simple antibiotic can reduce the adverse complications.

\section{References}

1. Nadler N, Salinas-Madrigal L, Charles A, Pollak V (1969) Acute glomerulonephritis during late pregnancy: report of a case. Obstet Gynecol 34: 277.

2. Singson E, Fisher KF, Lindheimer MD (1980) Acute poststreptococcal glomerulonephritis in pregnancy: case report with an 18-year follow-up. Am J Obstet Gynecol 137: 857-858.

3. Lou C, Tang Z, Chen D, Liu Z (2011) Long-term prognosis for Chinese adult patients with acute postinfectious glomerulonephritis. Clin Nephrol 76: 186-194.

4. Carapetis JR, Steer AC, Mulholland EK, Weber M (2005) The global burden of group A streptococcal diseases. Lancet Infect Dis 5: 685-694.

5. Dillion HC (1970) Streptococcal skin infection and glomerulonephritis. Postgraduate Med J 46: 641-652.

6. Trivedi SV, Vasava AH, Bhatia LC, Patel TC, Patel NK, et al. (2010) Plasma exchange with immunosuppression in pulmonary alveolar haemorrhage due to leptospirosis. Indian J Med Res 131: 429-433.

7. Melby PC, Musick WD, Luger AM, Khanna R (1987) Poststreptococcal glomerulonephritis in the elderly: Report of a case and review of the literature. Am J Nephrol 7: 235-240.

8. Kaplan AL, Smith JP, Tillman AJ (1962) Healed acute and chronic nephritis in pregnancy. Am J Obstet Gynecol 83: 1519. 